\title{
Comparison of the original Amsler grid with the preferential hyperacuity perimeter for detecting choroidal neovascularization in age-related macular degeneration
}

\author{
Comparação entre a tela de Amsler original e o perímetro de hiperacuidade \\ preferencial para a detecção de neovascularização de coróide secundária à \\ degeneração macular relacionada à idade
}

\author{
David Leonardo Cruvinel Isaac ${ }^{1}$ \\ Marcos Pereira de Ávila² \\ Arnaldo Pacheco Cialdini ${ }^{3}$
}

${ }^{1}$ Médico Assistente e Coordenador do Setor de Retina e
Vítreo do Centro de Referência em Oftalmologia da
Universidade Federal de Goiás - UFG - Goiânia (GO) -
Brasil.
${ }^{2}$ Professor Doutor e Chefe do Serviço de Oftalmologia
do Centro de Referência em Oftalmologia da UFG -
Goiânia (GO) - Brasil.
${ }^{3}$ Médico Assistente do Centro de Referência em Oftal-
mologia da UFG. Mestre em Medicina Tropical pela
UFG - Goiânia (GO) - Brasil.
Address for correspondence: David L. C. Isaac. Rua
T-38, 929 - Apto. 601 - Setor Bueno - Goiânia (GO) Zip
code $74223-040$
E-mail: cruvinelisaac@hotmail.com
Recebido para publicação em 25.11 .2006
Aprovação em 02.07.2007

Financial support: This study had no financial support from any source, public or private.

Nota Editorial: Depois de concluída a análise do artigo sob sigilo editorial e com a anuência do Dr. Roberto Abucham sobre a divulgação de seu nome como revisor, agradecemos sua participação neste processo.

\begin{tabular}{l} 
ABSTRACT \\
\hline Purpose: To compare the preferential hyperacuity perimeter (Preview \\
PHP; Carl Zeiss Meditec, Dublin, CA) with the original Amsler grid in the \\
detection of choroidal neovascularization (CNV) in patients with age- \\
related macular degeneration (AMD). Methods: Patients were classified \\
into groups, based on the severity of the age-related macular degeneration \\
and underwent preferential hyperacuity perimeter and Amsler grid testing. \\
High sensitivity and or high specificity of a method were defined as the \\
observation of at least $80 \%$ of each one the parameters. Results: Sixty-five \\
patients (65 eyes) were analyzed statistically. The sensitivity of detection \\
of choroidal neovascularization was $70 \%$ by the Amsler grid and $90 \%$ by \\
the preferential hyperacuity perimeter and the specificity of the Amsler \\
grid was $85.5 \%$ and that of the preferential hyperacuity perimeter $81.8 \%$. \\
Conclusions: Thepreferential hyperacuity perimeterhas greater sensitivity \\
than the Amsler grid in the detection of choroidal neovascularization \\
among patients over 50 years of age and is a promising method for \\
monitoring patients with age-related macular degeneration. Although \\
the original Amsler grid is less sensitive, it is a portable method, not \\
expensive, accessible and presents reasonable sensitivity and high \\
specificity in the diagnosis of choroidal neovascularization. Its use can \\
be recommended for self-monitoring in patients with age-related macular \\
degeneration as an alternative to preferential hyperacuity perimeter and \\
when this method is not available.
\end{tabular}

Keywords: Macular degeneration; Vision tests; Choroidal neovascularization; Perimetry/ methods; Patient selection; Comparative study

\section{INTRODUCTION}

Age-related macular degeneration (AMD) constitutes the greatest cause of legal blindness in the Western world, in people older than 65 years of age ${ }^{(1)}$. It is estimated that in the United States, approximately $6 \%$ of the population, over 40 years, present characteristics of intermediate AMD (at least 1 drusen higher than or equal to $125 \mu \mathrm{m}$ in one of the eyes) and that about $1 \%$ of the population, in this age bracket, present neovascular $\mathrm{AMD}^{(2)}$. The neovascular form of AMD is the one that is more closely related to the deterioration of 
central vision, being responsible for the majority of the cases of severe visual loss attributed to the disease ${ }^{(3)}$.

The current treatments available for neovascular AMD

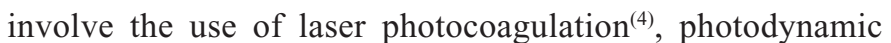
therapy with verteporfin ${ }^{(5)}$ and antiangiogenic treatment with pegaptanib $^{(6)}$ and ranibizumab ${ }^{(7)}$ besides drugs that are under investigation or in experimental use ${ }^{(8-9)}$. The importance of early recognition of the choroidal neovascularization (CNV) secondary to AMD was made evident by a study in which it was shown that photodynamic therapy showed better visual results when applied to the smaller lesions at the time of diagnosis ${ }^{(10)}$.

The Amsler grid was initially introduced in 1947 as a method for clinical evaluation of patients with macular diseases ${ }^{(11)}$. This device has been commonly used in clinical practice, especially for the self-monitoring of patients with non-neovascular AMD, alerting the patient to the possible appearance of CNV. Previously published studies, however, question the reliability of its use in the detection of macular afflictions, principally due to the possibility of the loss of fixation and the cortical completion phenomena described with its use $\mathrm{e}^{(12-14)}$.

The preferential hyperacuity perimeter (PreView PHP, Carl Zeiss Meditec, Dublin, CA) was developed for the monitoring and detection of the progression of AMD in the non-neovascular form to the neovascular form. The PHP is based on the principle of Vernier acuity or hyperacuity, that is the capacity to perceive a small difference in the spatial localization of two or more stimuli ${ }^{(15)}$. This property would permit the detection of an eventual metamorphopsia caused by the displacement of photoreceptors by the CNV or by the separation of the pigment epithelium or neurosensory retina caused by it.

Loewenstein et al. ${ }^{(16)}$, described the use of PHP for the first time in monitoring patients with AMD, having shown the greater sensitivity of the method in detecting macular alterations than the Amsler grid, whose results were later confirmed by a multicenter, controlled study. Recently, the high sensitivity and specificity of the method in the differentiation between patients with intermediate AMD and recent-onset CNV, were described ${ }^{(17)}$.

In the first two studies regarding the use of the $\mathrm{PHP}^{(15-16)}$, a greater sensitivity in the monitoring of patients with AMD by PHP than by the Amsler grid was found. However, both studies used the black-on-white Amsler grid (black grid on white background $)^{(18)}$. Recently, a comparsion of the use of the original Amsler grid (white grid on black background) and the modified Amsler grid (black-on-white) in patients with AMD was performed ${ }^{(11)}$. This study determined the higher sensitivity of the original Amsler grid than the modified Amsler grid, thereby recommending its use in the self-monitoring of macular diseases.

This study has the objective of comparing the original Amsler grid to the PHP in the detection of secondary CNV to AMD in a group of patients over 50 years of age and in different stages of AMD.

\section{METHODS}

This study was carried out in the Ophthalmology Department of the Federal University of Goias (Goiânia, Brazil) between June 1, 2005 and May 5, 2006. The protocol was previously approved by the Institutional Review Board (IRB)/ the Ethics Committee of this institution and all of the patients included in the study read and signed the informed consent.

The criteria for inclusion were over 50 years of age, best corrected visual acuity (BCVA) equal or better than 20/160 (0.125 decimal) and presumed physical and mental aptitude for performing the tests of PHP and the Amsler grid. Patients with visual acuity lower than 20/160 (minimum visual acuity described for the performing of PHP) were excluded from the sample ${ }^{(15,17)}$, as well as those with any macular disease other than AMD, media opacities that impede biomicroscopic evaluation of the macula or that impeded the carrying out of fundus photography, myopia higher than 6 diopters, patients who are recognized to have glaucoma, evidence of geographic atrophy (with diameter $\geq 100 \mu \mathrm{m}$ ) in the study eye, ocular surgery less than three months previously, vitreous-retinal or previous treatment for neovascular AMD at any time.

The patients were classified into groups: no AMD, mild AMD, intermediate AMD and neovascular AMD based on the definitions used in the AREDS study ${ }^{(19)}$ (Table1). All patients were examined and classified by one retinal specialist, later the classification was confirmed by a second and masked examiner through fundus photography analysis. In case there was no agreement about the diagnosis by the examiners, the patient was excluded from the analysis. After the fundoscopy examination, all patients were submitted to red-free and color fundus photography (Topcon TRC-50x/Imagenet 1024, Tokyo, Japan). Fluorescein angiography (FA) was performed if there was a suspicion of $\mathrm{CNV}$ or if the patient presented positive results in the PHP and or Amsler grid examinations. This analysis defined the gold standard parameter for later statistical analysis. If a patient presented both eyes eligible for the study, one of the eyes was included randomly, except if one of the eyes presented CNV, which would fall within the

\begin{tabular}{|ll|}
\hline Group & Table 1. Definitions of patient groups \\
No AMD & \multicolumn{1}{c|}{ Definition } \\
Mild AMD & $\begin{array}{l}\text { Less than } 5 \text { small drusen }(<63 \mu \mathrm{m}) \\
\text { within } 3000 \mu \mathrm{m} \text { from foveal center in } \\
\text { the study eye } \\
\text { More than } 5 \text { small drusen and/or less } \\
\text { than } 5 \text { intermediate drusen }(\geq 63 \mu \mathrm{m} \\
\text { but } \leq 125 \mu \mathrm{m}) \text { within } 3000 \mu \mathrm{m} \text { from } \\
\text { foveal center in the study eye } \\
\text { More than } 5 \text { intermediate drusen and } \\
\text { any large drusen }(\geq 125 \mu \mathrm{m}) \text { within } \\
3000 \mu \mathrm{m} \text { from foveal center in the study } \\
\text { eye } \\
\text { Active CNV with less than } 50 \% \text { fibrotic } \\
\text { component and visual acuity } \geq 20 / 160\end{array}$ \\
\hline
\end{tabular}


criteria for inclusion. In these cases, the eye with $\mathrm{CNV}$ was the included one.

\section{Amsler grid testing}

A white grid on a black background was used. The grid represents a 10x10 cm square containing 400 single squares equally distanced with a white dot (fixation point) in the center of the grid. A single examiner presented the Amsler test to the patient using a +3.00 diopters addition to the patient's refraction ( $33 \mathrm{~cm}$ from patients' eyes). Five standard questions were asked based on questions from a previous study $^{(15)}$ (Table 2). If any scotoma, blurred lines or metamorphopsia were detected the test was considered positive. All patients were tested with undilated pupils.

\section{PHP testing}

The PHP tests have a central visual field with approximately 500 data points sampled 3 to 5 times. Multiple dotted lines with artificially generated distortions are presented, flashed in an order that appears to be random to an obser$\operatorname{ver}{ }^{(17)}$. The patient is asked to touch the screen right on the distorted lines. During a brief tutorial it is explained that multiple distortions or even none at all could be seen on the dotted lines. After 46 to 102 presented signals the internal algorithm compares the visual field defect intensity to a normative database and following the algorithm analysis, the result indicates Yes or No for detection of $\mathrm{CNV}^{(15,17)}$. All patients had undilated pupils. If any test was considered unreliable, the results were excluded from the sample. In table 3 the reliability criteria from the findings of false positive and false negative, described in the instructions for using the machine are listed.

\section{Statistical analysis}

Total accuracy, sensitivity, and specificity were calculated with their respective 95\% confidence intervals on the Amsler grid and the PHP in the detection of CNV. The area under the ROC curve was used to determine accuracy. High sensitivity and or high specificity of a method were defined as the observation of at least $80 \%$ of each of the parameters, with $95 \%$ confidence intervals. Only the age variable showed a normal distribution by the Kolmogorov-Smimoff test, being analyzed

\section{Table 2. Questions presented during Amsler grid test}

1. Do you see the white spot in the center of the square chart?

2. Keeping your eye fixed on the white spot, can you see the four corners of the squares?

3. Keeping your eye fixed on the white spot, can you see all the small squares? Are they intact?

4. Keeping your eye fixed on the white spot, can you see any black spots or holes, blurred areas or distorted lines?

5. Keeping your eye fixed on the white spot, would you be able to point the defects exact location on the grid? (Asked if there was an affirmative answer to question 4)

\begin{tabular}{|ccccc|}
\hline Table 3. Reliability of a PHP examination based on findings of false \\
positives and negatives \\
$\begin{array}{c}\text { False Positive/ } \\
\text { False Negative }\end{array}$ & 1 & 2 & 3 & $\begin{array}{c}\text { None } \\
\text { detected }\end{array}$ \\
$\begin{array}{c}\text { PHP result= Yes } \\
1\end{array}$ & Reliable & Unreliable & Unreliable & Reliable \\
2 & Reliable & Unreliable & Unreliable & Unreliable \\
3 & Unreliable & Unreliable & Unreliable & Unreliable \\
PHP result=No & & & & \\
1 & Reliable & Reliable & Unreliable & Reliable \\
2 & Unreliable & Unreliable & Unreliable & Unreliable \\
3 & Unreliable & Unreliable & Unreliable & Unreliable \\
\hline
\end{tabular}

by the analysis of variance (ANOVA). All other variables, not parametric, were evaluated by the Kruskall-Wallis test. A $\mathrm{p}<0.05$ or a confidence interval (CI) of $95 \%$ was considered significant. The SPSS software, version 11.0.1 (SPSS Inc, Chicago, IL, USA) was used for the statistical analysis.

\section{RESULTS}

Sixty-five patients (65 eyes) were statistically analyzed, after the criteria of inclusion/exclusion were applied, agreement between the examiners as to the definition of the groups and the patients excluded for not obtaining reliable tests (reliability). Of these, 34 (52.3\%) were women. The mean age $\pm \mathrm{SD}$ was 67 years \pm 8.15 (range, 55-85 years). Best corrected visual acuity (decimal) ranged from 1.0 to 0.15 (median 0.8 ). The distribution of the number of patients, sex, average age and visual acuity in the groups can be found listed in table 4 . There was no difference among the groups in relation to the age $(\mathrm{p}=0.09)$ and sex $(\mathrm{p}=0.73)$. There was a statistically significant difference in relation to visual acuity $(p<0.01)$.

From the total number of analyzed patients, $15(23.1 \%)$ were positive in the Amsler grid and 19 (29.2\%) were positive in PHP. In the no AMD group there were no positive patients in the Amsler grid and 4 patients $(26.7 \%)$ were positive in PHP. In the mild AMD group 4 patients were positive in the Amsler grid and 4 patients (18.2\%) were positive in PHP. Among the patients from the intermediate AMD group, 4 patients $(22.2 \%)$ were positive in the Amsler grid and 2 patients $(11.1 \%)$ were positive in PHP, while in the neovascular AMD group 7 patients $(70 \%)$ were positive in the Amsler grid and 9 patients $(90 \%)$ were positive in PHP.

The detection sensitivity for CNV among the studied patients was 70\% (95\% confidence interval [CI], 58.9\%$81.1 \%$ ) in the Amsler grid and 90\% (95\% CI, 82.7\%-97.3\%) in PHP. The specificity of the Amsler grid was $85.5 \%(95 \%$ CI, 76.9\%-94.1\%) and of the PHP 81.8\% (95\% CI, 74.4\%91.2\%). The accuracy of the Amsler grid was 77.7\% (95\% CI, 60.1\%-95.4\%) and of the PHP 85.9\% (95\% CI, 73.5\%-98.4\%). There was no significant statistical difference between the specificity and the accuracy of the methods. In figure 1 one 


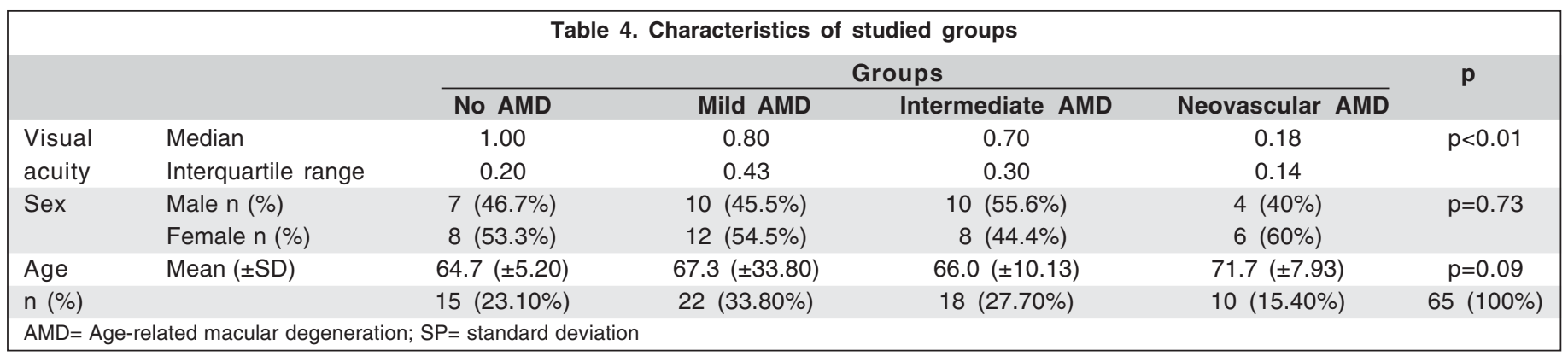

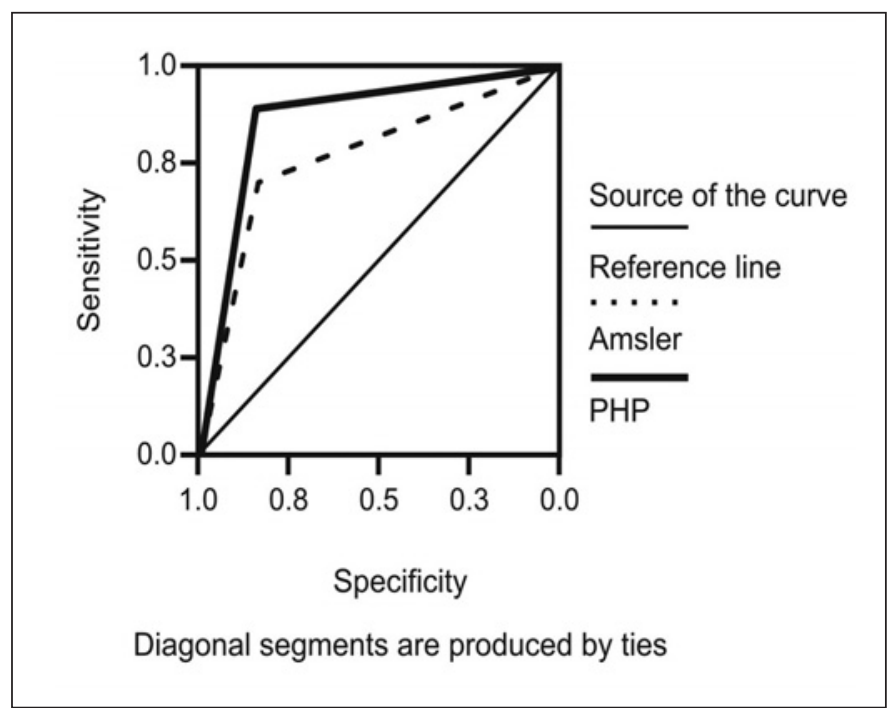

Figure 1 - ROC curve of PHP and Amsler grid

can observe the pattern of the ROC curve on comparison between the Amsler grid and the PHP with the gold standard.

\section{DISCUSSION}

This study shows that PHP presents a greater sensitivity than the original Amsler grid in the detection of CNV secondary to AMD. However, there was no statistically significant difference between the methods in relation to specificity and accuracy.

A previous study that compared the use of PHP to the angiographic diagnosis of $\mathrm{CNV}^{(17)}$ determined the high sensitivity ( $82 \%$ [95\% CI, 70\%-90\%]), specificity ( $88 \%$ [95\% CI, $76 \%-95 \%]$ ) and accuracy of $84 \%$ of PHP in the detection of $\mathrm{CNV}$ in a group made up of patients with intermediate AMD and recent-onset neovascular AMD. The results obtained by PHP in that study were similar to those obtained in the present study, sensitivity (90\%), specificity $(81.8 \%)$ and accuracy $(85.9 \%)$. This study however, evaluated the capacity of detection of CNV comparing the PHP to the gold standard (diagnosis of CNV). In that study, however, there was no comparison of PHP to another existing method of monito- ring, such as the Amsler grid. When we compare the PHP to the original Amsler grid the PHP proved itself to have greater sensitivity than the original Amsler grid in the diagnosis of $\mathrm{CNV}$ among patients over 50 years of age. However there was no difference, in this sample, regarding the specificity and accuracy of the two methods in the diagnosis of CNV.

A multicenter clinical trial ${ }^{(15)}$ compared PHP to the modified Amsler grid (black grid on white background) in patients with AMD. In this study the greater sensitivity of the PHP in relation to the Amsler grid was observed in the detection of AMD-related lesions. The authors observed $100 \%$ positivity with PHP and 53\% with the use of the modified Amsler grid in patients with CNV. The difference in sensitivity with the Amsler grid in Goldstein's study compared to our study may be explained by Augustin's finding of a greater sensitivity of the original Amsler grid than the modified grid $^{(11)}$.

In a retrospective study ${ }^{(20)}$, it was reported that 29 in 100 new cases of CNV attended in one institution had sought treatment after having perceived alterations in the examination with the original Amsler grid. All 100 patients had been instructed in previous consultations about the use of the Amsler grid for self-monitoring. In Goldstein's study ${ }^{(15)}$ the modified Amsler grid was used, having observed positivity in $53 \%$ of the patients with CNV, while in the present study $70 \%$ of positivity was found when the original grid was used. A different study design and analysis of the data do not permit a direct comparison between the studies, but in the last two the performance of the examination under the orientation and observation of an examiner, with the asking of standard questions and constant observation of the fixation of the patient may have been responsible for the greater sensitivity of the method in the detection of CNV.

The PHP has been designed to detect the progression of non-neovascular AMD to the neovascular form. In this study, however, positive results were observed in all the groups of patients with non-neovascular AMD in PHP even without evidence of CNV on fluorescein angiography (FA). Among the studied groups positivity of PHP was observed in 4 (26.7\%) patients in the no AMD group, $4(18.2 \%)$ in the mild AMD group and $2(11.2 \%)$ patients in the intermediate AMD group. All tested patients were submitted to the PHP examination for the first time. It is possible that, the similarity to the other types of perimetry, the PHP also presents the so 
called "learning effect" in which the findings of the following examinations become even better than those obtained with the dependable baseline ${ }^{(21-22)}$.

Some limitations can be identified in the present study. Besides the relatively small number of analyzed patients, we can mention the fact that the examiner responsible for applying PHP and the Amsler grid was aware of the diagnosis. The FA is recognized as the gold standard for the diagnosis of CNV secondary to $\mathrm{AMD}^{(15)}$. However in this study the FA was used in cases of clinical suspicion of CNV or when PHP or Amsler grid test showed positive results. Not performing FA in all patients may have allowed for missing the diagnosis of CNV in some subtle cases.

\section{CONCLUSION}

The PHP is a relatively new and promising diagnostic method, designed for the monitoring of patients with nonneovascular AMD, and has as its purpose the early diagnosis of the progression to neovascular AMD. In this study it showed its greater sensitivity in the detection of CNV than the original Amsler grid, observing the high sensitivity and the high specificity in its use. In spite of being less sensitive, the original Amsler grid is a portable method, inexpensive, accessible and presents reasonable sensitivity and high specificity in the diagnosis of CNV. Its use can be recommended for self-monitoring in patients with age-related macular degeneration as an alternative to PHP and when this method is not available.

\section{RESUMO}

Objetivo: Comparar o perímetro de hiperacuidade preferencial (Preview PHP; Carl Zeiss Meditec, Dublin, Califórnia EUA) com a tela de Amsler original na detecção de neovascularização de coróide (NVC) em pacientes com degeneração macular relacionada à idade (DMRI). Métodos: Os pacientes foram classificados em grupos baseados no grau de gravidade da degeneração macular relacionada à idade e foram submetidos aos testes do perímetro de hiperacuidade preferencial e da tela de Amsler. Estabeleceu-se como alta sensibilidade e/ ou alta especificidade de um dos métodos, a observação de pelo menos $80 \%$ de cada um dos parâmetros. Resultados: Sessenta e cinco pacientes (65 olhos) foram analisados estatisticamente. A sensibilidade de detecção de neovascularização de coróide foi de $70 \%$ pela tela de Amsler e $90 \%$ pelo perímetro de hiperacuidade preferencial, ao passo que a especificidade da tela de Amsler foi de $85,5 \%$ e do perímetro de hiperacuidade preferencial $81,8 \%$. Conclusões: O perímetro de hiperacuidade preferencial apresenta maior sensibilidade que a tela de Amsler original na detecção de neovascularização de coróide entre pacientes com idade superior a 50 anos e constitui um método promissor no monitoramento de pacientes com degeneração macular relacionada à idade.
Apesar de a tela de Amsler original ser menos sensível, é método portátil, financeiramente acessível, e apresenta razoável sensibilidade e alta especificidade no diagnóstico da neovascularização de coróide. Sua utilização pode ser recomendada para o automonitoramento de pacientes com degeneração macular relacionada à idade como alternativa ao perímetro de hiperacuidade preferencial.

Descritores: Degeneração macular; Testes visuais; Neovascularização coroidal; Perimetria/métodos; Seleção de pacientes; Estudo comparativo

\section{REFERENCES}

1. Klein R, Klein BE, Linton KL. Prevalence of age-related maculopathy. The Beaver Dam Eye Study. Ophthalmology. 1992;99(6):933-43.

2. Friedman DS, O'Colmain BJ, Munoz B, Tomany SC, McCarty C, de Jong PT, et al. Prevalence of age-related macular degeneration in the United States. Eye Diseases Prevalence Research Group. Arch Ophthalmol. 2004;122(4):564-72.

3. Loewenstein A, Bressler NM. Neovascular (exudative) age-related macular degeneration. In: Guyer D, editor. Retina-vitreous-macula. Philadelphia, PA: W.B.Saunders; 1999. p.94-121.

4. Subfoveal neovascular lesions in age-related macular degeneration. Guidelines for evaluation and treatment in the Macular Photocoagulation Study. Macular Photocoagulation Study Group. Arch Ophthalmol. 1991;109(9):1242-57.

5. Verteporfin Roundtable Participants. Guidelines for using verteporfin (Visudyne) in photodynamic therapy for choroidal neovascularization due to age-related macular degeneration and other causes: update. Retina. 2005;25(2):119-34. Review.

6. Gragoudas ES, Adamis AP, Cunningham ET Jr, Feinsoid M, Guyer DR; VEGF Inhibition Study in Ocular Neovascularization Clinical Trial Group. Pegaptanib for neovascular age-related macular degeneration. New Engl J Med. 2004;351(27):2805-16.

7. Heier JS, Antoszyk NA, Pavan PR, Leff SR, Rosenfeld PJ, Ciulla TA, et al. Ranibizumab for treatment of neovascular age-related macular degeneration: a phase I/II multicenter, controlled, multidose study. Ophthalmology. 2006; 113(4):633-642.

8. Spaide RF, Laud K, Fine HF, Klancnik JM Jr, Meyerle CB, Yannuzzi LA, et al. Intravitreal bevacizumab treatment of choroidal neovascularization secondary to age-related macular degeneration. Retina. 2006;26(4):383-90.

9. Rosenfeld J, Moshfeghi AA, Puliafito CA. Optical coherence tomography findings after an intravitreal injection of bevacizumab (avastin) for neovascular age-related macular degeneration. Ophthalmic Surg Lasers Imaging. 2005;36(4):331-5.

10. Blinder KJ, Bradley S, Bressler NM, Bressler SB, Donati G, Hao Y, Ma C, Menchini U, Miller J, Potter MJ, Pournaras C, Reaves A, Rosenfeld PJ, Strong HA, Stur M, Su XY, Virgili G. Treatment of Age-related Macular Degeneration with Photodynamic Therapy study group; Verteporfin in Photodynamic Therapy study group. Effect of lesion size, visual acuity, and lesion composition on visual acuity change with and without verteporfin therapy for choroidal neovascularization secondary to age-related macular degeneration: TAP and VIP report no. 1. Am J Ophthalmol. 2003;136(3): 407-18.

11. Augustin AJ, Offermann JL, Lutz J, Schmidt-Erfurth U, Tornambe P. Comparsion of the original Amsler grid with the modified Amsler grid. results for patients with age-related macular degeneration. Retina. 2005;25(4):443-5.

12. Fine AM, Elman MJ, Ebert JE, Prestia PA, Starr JS, Fine SL. Earliest symptoms caused by neovascular membranes in the macula. Arch Ophthalmol. 1986;104(4):513-4.

13. Schuchard RA. Validity and interpretation of Amsler grid reports. Arch Ophthalmol. 1993;111(6):776-80.

14. Achard OA, Safran AB, Duret FC, Ragama E. Role of the completion phenomenon in the evaluation of Amsler grid results. Am J Ophthalmol. 1995; 120(3):322-9

15. Goldstein M, Loewenstein A, Barak A, Pollack A, Bukelman A, Katz H, Springer A, Schachat AP, Bressler NM, Bressler SB, Cooney MJ, Alster Y, Rafaeli O, Malach R; Preferential Hyperacuity Perimeter Research Group. Results of a multicenter clinical trial to evaluate the preferential hyperacuity perimeter for detection of age-related macular degeneration. Retina. $2005 ; 25(3): 296-303$ 
776 Comparison of the original Amsler grid with the preferential hyperacuity perimeter for detecting choroidal neovascularization in age-related macular degeneration

16. Loewenstein A, Malach R, Goldstein M, Leibovitch I, Barak A, Baruk E, et al. Replacing the Amsler grid: a new method for monitoring patients with age-related macular degeneration. Ophthalmology. 2003;110(5):966-70.

17. Alster Y, Bressler NM, Bressler SB, Brimacombe JA, Crompton RM, Duh YJ, Gabel VP, Heier JS, Ip MS, Loewenstein A, Packo KH, Stur M, Toaff T; Preferential Hyperacuity Perimetry Research Group. Preferential Hyperacuity Perimeter (PreView PHP) for detecting choroidal neovascularization study. Ophthalmology. 2005;112(10):1758-65.

18. Lewenstein A, Malach R, Goldstein M, Leibovitch I, Barak A, Baruch E, et al. Replacing the Amsler grid: a new method for monitoring patients with age-related macular degeneration. Ophthalmology. 2003;110(5):966-70. Comment in: Ophthalmology. 2005;112(2):357; author reply 357.
19. Age-Related Eye Disease Study Research Group. A randomized, placebocontrolled, clinical trial of high-dose supplementation with vitamins $\mathrm{C}$ and $\mathrm{E}$, beta carotene, and zinc for age-related macular degeneration and vision loss: AREDS report no. 8. Arch Ophthalmol. 2001;119(10):1417-36.

20. Zaidi FH, Cheong-Leen R, Gair EJ, Weir R, Sharkawi E, Lee N, et al. The Amsler chart is of doubtful value in retinal screening for early laser therapy of subretinal membranes. The West London Survey. Eye. 2004;18(5):503-8.

21. Werner EB, Adelson A, Krupin T. Effect of patient experience on the results of automated perimetry in clinically stable glaucoma patients. Ophthalmology. 1988;95(6):764-7.

22. Heijl A, Lindgren G, Olsson J. The effect of perimetric experience in normal subjects. Arch Ophthalmol. 1989;107(1):81-6. 